\title{
Influence of optimized lubrication-cooling and minimum quantity lubrication on the cutting forces, on the geometric quality of the surfaces and on the micro-structural integrity of hardened steel parts
}

\author{
M.C.S. ALVES ${ }^{\mathrm{I}}$, E.C. BIANCHI ${ }^{\mathrm{II}}$, P.R. AGUIAR ${ }^{\mathrm{II}}$, R.C. CANARIM ${ }^{\mathrm{II}}$ \\ IUNESP - São Paulo State University - Faculty of Industrial Wood Engineering \\ e-mail: manoel@itapeva.unesp.br \\ ${ }^{\mathrm{II}}$ UNESP - São Paulo State University - UNESP’s Bauru School of Engineering \\ e-mail: bianchi@feb.unesp.br ; aguiarpr@feb.unesp.br ; rubenscanarim@hotmail.com
}

\begin{abstract}
The is paper presents an analysis of the influence of minimum quantity lubrication (MQL), optimized and conventional cooling, using different cutting fluid volumes and flow rates, on the surface quality and integrity of hardened steel workpieces, in cylindrical plunge grinding with superabrasive CBN grinding wheels. The final quality of the workpieces were evaluated based on an assessment of output variables such as the behavior of: tangential cutting force, specific energy, surface roughness, roundness errors, acoustic emission, residual stresses, scanning electron microscopy (SEM) micrographs, and microhardness. The present analysis of the various forms of cutting fluid application identified cooling conditions which favor the minimization of cutting fluid usage, and shorter machining times without impairing the geometrical and dimensional parameters, surface finish and surface integrity of the workpieces. Among the various forms of cutting fluid application, optimized lubrication at higher outlet speeds showed the best performance, confirming the efficiency of the new nozzle concept employed in this study. The optimized and MQL processes were successful in maintaining the hardness and surface integrity of the ground workpieces. The only exception was the use of MQL with a flow rate of $40 \mathrm{ml} / \mathrm{h}$, which caused cracking and quenching of the workpiece surface. The lowest surface roughness values obtained with MQL were obtained using higher flow rates of lubricant. The surface roughness values obtained with MQL are high for the grinding process. Low-concentration CBN wheels, which are less expensive and subject to less wear, produce good results when associated with more efficient cutting fluid application techniques.
\end{abstract}

Keywords: Grinding, CBN, grinding wheel, minimum quantity lubricant (MQL), conventional lubrication, optimized lubrication.

\section{$1 \quad$ INTRODUCTION}

The worldwide tendency is to produce increasingly more sophisticated parts with very strict geometrical, dimensional and surface finish tolerances, at low costs and without harming the environment. However, several machining processes, including grinding, make use of cutting fluids to lubricate and cool the workpiece. In these manufacturing processes, if lubrication and cooling are not satisfactory, the high temperatures generated may damage the resulting workpiece in several ways, such as: surface burns, microstructural changes, residual stresses, shape errors, and even deterioration of the final quality of the workpiece [1, 2].

Cutting fluids are frequently disposed directly into the environment, which is currently an inappropriate practice considering the Earth's current situation and today's restrictive environmental regulations and man's growing environmental awareness. Moreover, the relative cost of cutting fluid management increases continually due to its high consumption rate and the treatment it must undergo prior to disposal, in order to meet environmental regulations. Large amounts of cutting fluids are necessary to meet the requirements of an increasing industrial productivity and of machining processes []]

Furthermore, many cutting fluids impair the health of machine operators, who are subject constantly to physical contacts with these fluids. However, this problem is being diminished through the use of vegetalbased cutting fluids, which are less harmful to human health.

Thus, the overall use of cutting fluids tends to decline over time, making necessary to engage in research on this subject, in order to minimize the part taken by these fluids in productive processes, and 
hence, in the environment. To this end, more analyses are needed about the consequences of this type of alteration on the final state of machined components.

Efforts to reduce the use of lubricant in machining processes are being made from the viewpoint of cost, ecology and health. Noting this tendency, this paper aims to study the replacement of conventional cooling for optimized cooling and minimum quantity of lubrication in the grinding process. This finishing process minimizes the surface roughnesses and irregularities through interactions between the abrasive grains of a tool (grinding wheel) and the workpiece to be ground $[\underline{4}, \underline{5}]$.

Conventional cooling consists of the application of cutting fluid under low pressure, low velocity, and high flow rates. The conventional method is the most applied industrially [ 6 ].

Conventional methods of fluid application systems are relatively inefficient in severe conditions of the grinding process. This method does not allow the fluid jet to disrupt the air barrier formed around the grinding wheel, due to its high rotation $[\underline{7}, \underline{8}]$.

The minimum quantity of lubrication (MQL) is obtained by mixing cutting fluid droplets with compressed air. The MQL method in grinding is much more challenging than in any other cutting processes, and only a few researchers have contributed to this subject so far. MQL has shown good results in conventional machining processes, but is little explored in complex cases such as grinding $[\underline{9}, \underline{10}]$.

MQL can be considered as one of the solutions to reduce the amount of lubricant used, and it is being studied in various machining process. When properly applied, both parts and chips remain dry and are easier to handle [11].

The optimized method applies the cutting fluid directly on the cutting area, at high outlet speeds. This optimization generates less fluid jet dispersion in the cutting zone and increases the lubricating and cooling capacity of the fluids, easing the removal of chips [12].

In view of the above, it is evidently important to evaluate the quality of workpieces produced by more efficient cutting fluid application methods. The present research involved the use of three methods in order to evaluate workpiece wear (the conventional method, the optimized method - with a nozzle similar to that proposed by Webster, and the minimum quantity lubrication - MQL method), using CBN wheels with low abrasive concentrations $[\underline{13}, \underline{14}]$.

Cutting fluids which cause low environmental and health impacts were used in this research. Based on the quality of the ground workpieces attained with these fluids, their use should be widespread, contributing significantly to the process and to society as a whole $[\underline{15}, \underline{16}]$.

Another noteworthy aspect of this work is the use of innovative concepts concerning the lubrication methods used in the grinding process, which can be extended to other processes that also use cutting fluids. The lubrication/cooling methods currently in use (conventional, minimum quantity lubrication, and optimized) are aimed at meeting real industrial conditions. It was therefore necessary to study and design suitable nozzles based on new geometries and designs not commercially available.

Another objective regarding innovation was the amount of abrasive material in the grinding wheel. One of the reasons that hinder the wider use of CBN grinding wheels is the fact that they are much more expensive than conventional wheels, and their cost depends on the quantity of CBN grains they contain. In this research, a CBN grinding wheel with $15 \%$ volume concentration of abrasive grains was used, seeking a more economic alternative for the fabrication of ground workpieces.

This way, the main objective of this work was to evaluate the quality of ground workpieces using three cutting fluid application methods, in the external plunge cylindrical grinding of ABNT 4340 steel, with two types of fluids which are less harmful to the environment and to human health, and a superabrasive CBN tool with low concentration of abrasives. The three lubrication/cooling techniques used here were the minimum quantity lubrication (MQL) method, the optimized lubrication/cooling method (OM), and the conventional lubrication/cooling method (CM), using new nozzle designs for industrial settings. Efforts focused on finding a compromise between quality, cost, and environmental concerns applied to more efficient lubrication/cooling systems through innovative nozzles designed for industrial use. The influence on quality was evaluated based on analyses of surface roughness, roundness errors, tangential cutting force, acoustic emission signals, residual stresses, scanning electron microscopy (SEM) micrographs, and the microhardness of test specimens.

\section{EXPERIMENTAL PROCEDURE}

In this research, three distinct cutting fluid application techniques were used, i.e., the conventional method (CM) using two circular nozzles; the minimum quantity lubrication (MQL) method, using a nozzle designed specifically for this type of application; and the optimized method (OM), using a new nozzle designed specifically to cover the entire grinding surface.

A RUAP 515 H-CNC grinding machine (SULMECÂNICA, Cachoeirinha, RS, Brazil) was used, equipped with a computer numerical control (CNC) (FAGOR AUTOMATION DO BRASIL, São Paulo, SP, 
Brazil) [17]. Fifty workpieces were ground, 15 using MQL, 25 using the OM, 5 using the CM, and 5 dry (without lubricant/coolant).

Test Specimens: The test specimens were made of quenched and annealed ABNT 4340 steel. This material is widely used in the manufacture of parts that require a good combination of strength and toughness, with relatively uniform values throughout the cross section.

Cutting Fluids: Vegetable oil emulsion (based on synthetic esters), specification DMS 3200 F-1 Lot 0193/06-S manufactured by Shell do Brasil S.A. [18], used in the conventional and optimized lubricant dispensing methods. A 5\% concentration, $\mathrm{pH}$ 9, was used. The cutting fluid used for the MQL method was Accu-Lube LB 1000 Lot 39540 manufactured by ITW Chemical Products Ltda. [19]. The fluid was controlled microbiologically using ADEP 30 triazine bactericide.

Cutting Tool: The tests were carried out with a superabrasive CBN (cubic boron nitride) grinding wheel manufactured with vitrified binder and a 15\% volume concentration of CBN, having the following characteristics: 350 x 20 - 5 x 127 - SNB151Q12VR2 - lot 7936, with an open structure of fine hard grains.

According to Upadhyaya and Malkin [10], CBN grinding wheel is considered for MQL grinding because CBN grains have very high thermal conductivity, which can enhance heat conduction away from the grinding zone (to the wheel) and therefore can prevent thermal damages to the workpiece.

Vitrified bonded wheels are currently used for high speed grinding. They present a high level of resistance and they can be easily dressed. Their porosity can be adjusted. CBN grains are harder than conventional abrasives and their wear behavior is different (SINOT et al. 2006).

Conventional lubrication/cooling: Characterized by the application of cutting fluid under low pressure, low velocity, and high flow rate. The nozzle used in this system consists of two misting nipples, each $6.3 \mathrm{~mm}$ in diameter, for the outlet of fluid.

Minimum quantity lubrication - MQL: Characterized by an aerosol of cutting fluid droplets and compressed air. The system consists basically of a compressor, pressure regulator, air flow meter, doser, and nozzle designed for the use of MQL in grinding (Figure 1). The MQL system allows for the lubricant/air ratio to be finely regulated.
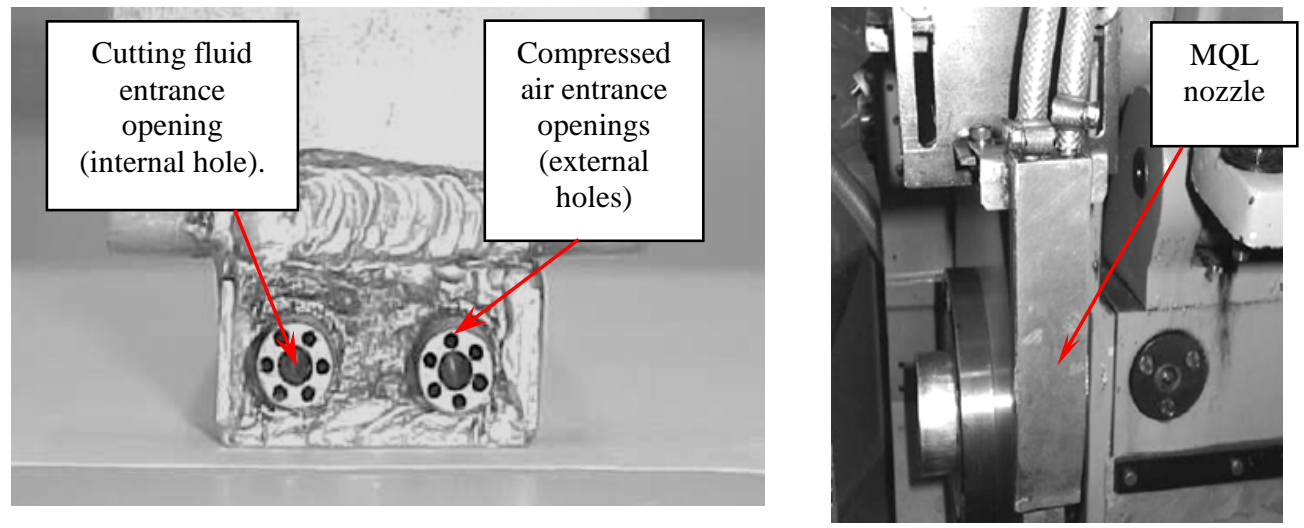

Figure 1: View of the rear portion of the MQL nozzle, showing the compressed air and cutting fluid entrance openings as well as the nozzle used in the MQL experiment performed on the grinding wheel.

Optimized system: Characterized by high cutting fluid flow rate and high pressure. The system consists basically of an optimized nozzle designed from an MQL nozzle. A rectangular tube made of galvanized ABNT 1010 sheet steel. Figure 2 illustrates the optimized nozzle fabricated and used in this study.

According to Webster et al. (1995) [5] , lubrication and cooling depend on the effective delivery of fluid at the workpiece-tool interface, end high volumes are not necessary since part of the fluid does not actually penetrate the cutting region. However, the type of nozzle end its positioning strongly afecct the cutting process. Application nozzles designed to avoid turbulence present the best effect, since they tend to approach the fluid films formed inside the nozzle.

The machining conditions used in the testes were as follows: Plunge velocity (Vf) of $1 \mathrm{~mm} / \mathrm{min}$; Cutting speed (Vs) of 30m/s; Workpiece rotation ( $\omega \mathrm{w})$ of $204 \mathrm{rpm}$; Penetration depth (a) of 0.1mm; Sparkout time (ts) of 8 seconds; Grinding width of 12mm; Grinding cycles of 100; Maximum equivalent cutting thickness (heq) of $0.065 \mu \mathrm{m}$; Minimum equivalent cutting thickness of $0.047 \mu \mathrm{m}$; fleece dresser.

Tables 1, 2 and 3 list the cutting fluid velocities and flow rates in the optimized, MQL and conventional conditions, respectively. It should be noted that the concentration of fluid used in the optimized and conventional techniques was kept constant at $5 \%$. 


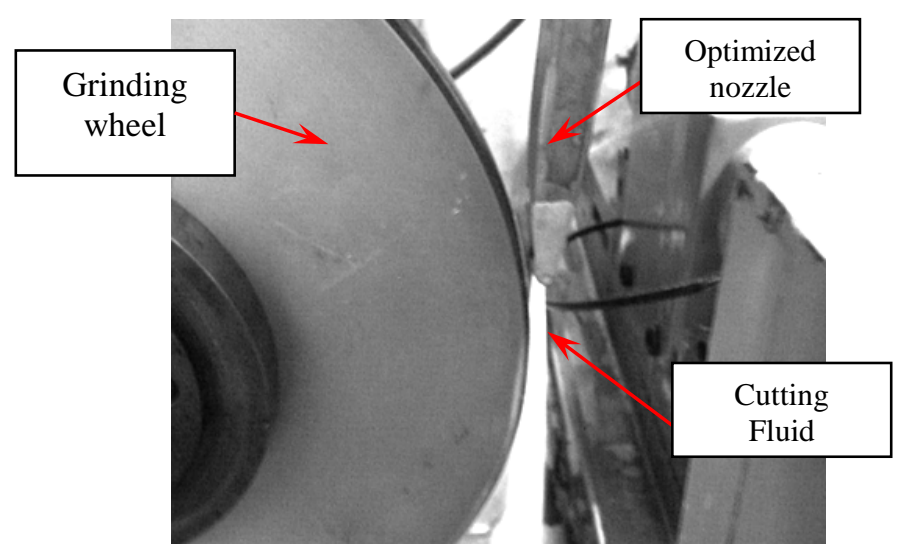

Figure 2: Optimized nozzle and view of the jet it produces.

Table 1: Speeds and flow rates used in the optimized application method.

\begin{tabular}{c|c|c}
\hline $\begin{array}{c}\text { Flow speed used } \\
\text { in used in optimized } \\
\text { conditions (m/s) }\end{array}$ & $\begin{array}{c}\text { Total cutting fluid } \\
\text { flow (l/min) }\end{array}$ & $\begin{array}{c}\text { Fluid flow velocity, } \\
\text { Vj (m/s) }\end{array}$ \\
\hline 30 & 26.3 & 30 \\
\hline 27 & 23.7 & 27 \\
\hline 25 & 21.9 & 25 \\
\hline 20 & 17.5 & 20 \\
\hline 15 & 13.2 & 15 \\
\hline
\end{tabular}

Table 2: Flow rates used in the MQL application method.

\begin{tabular}{c|c|c}
\hline $\begin{array}{c}\text { Flow rate used in MQL } \\
(\mathrm{ml} / \mathrm{h})\end{array}$ & $\begin{array}{c}\text { Total cutting fluid } \\
\text { flow }(\mathrm{l} / \mathrm{min})\end{array}$ & $\begin{array}{c}\text { Compressed air exit } \\
\text { velocity } \mathrm{Vj},(\mathrm{m} / \mathrm{s})\end{array}$ \\
\hline 40 & 0.00067 & 30 \\
\hline 60 & 0.00100 & 30 \\
\hline 80 & 0.00133 & 30 \\
\hline
\end{tabular}

Table 3: Speeds and flow rates used in the conventional application method.

\begin{tabular}{c|c|c}
\hline Conventional application & $\begin{array}{l}\text { Total cutting fluid } \\
\text { flow (l/min) }\end{array}$ & $\begin{array}{c}\text { Cutting fluid flow } \\
\text { velocity, } \mathrm{Vj},(\mathrm{m} / \mathrm{s})\end{array}$ \\
\hline Conventional & 20 & 5.3 \\
\hline
\end{tabular}

Measurement of tangential cutting force: The tangential cutting force, Ftc, was measured from the electrical power consumed by the motor of the grinding wheel axletree by monitoring the values of electrical voltage and current from this electrical motor.

Acoustic emission (AE) signal: This signal was monitored in real time based on its mean quadratic value (RMS, or Root Mean Square), using a SENSIS BM12 acoustic emission sensor. Parameters employed: signal gain: $3 \mathrm{~dB}$; noise reduction: $30 \mathrm{~dB}$; entrance gain: $3 \mathrm{~dB}$; and time constant: $1 \mathrm{~ms}$.

Surface roughness: The mean surface roughness of the workpieces, represented by the parameter Ra, was measured with a Taylor Hobson SURTRONIC 3+ surface roughness meter. Measurements were taken perpendicular to the grinding surface. The cut-off was $0.8 \mathrm{~mm}$ and the filter was a $2 \mathrm{CR}$ with phase correction. The diamond tip of the profilometer had a radius of $0.2 \mu \mathrm{m}$.

Roundness errors: These errors were measured with a Taylor Hobson TALYROND 31C roundness measuring instrument using TR31 software installed in a microcomputer coupled to the roundness meter. 
Residual stress: This stress was measured with a Siemens D5000 diffractometer with cobalt target X-ray tubes and a Rigaku D/Max-2000 diffractometer with chromium target X-ray tubes. The multiple exposure method (sen $2 \psi$ ) of X-ray diffraction was used.

Scanning electron microscopy (SEM): a ZEISS DSM 960 scanning electron microscope was used with $2000 \mathrm{X}$ magnification, applying the electron scattering technique, which offers a better view of the profile of the structures on the analyzed surface.

Microhardness: Microhardness was measured with a BUEHLER 1600-6300 microhardness tester, applying a load of $200 \mathrm{~g}$ for $40 \mathrm{~s}$.

\section{RESULTS AND DISCUSSION}

\subsection{Tangential Cutting Force}

Figures 3 and 4 show the maximum mean tangential cutting forces of the five repetitions carried out for each of the MQL, OM and CM conditions, allowing for an evaluation and comparison of the methods.

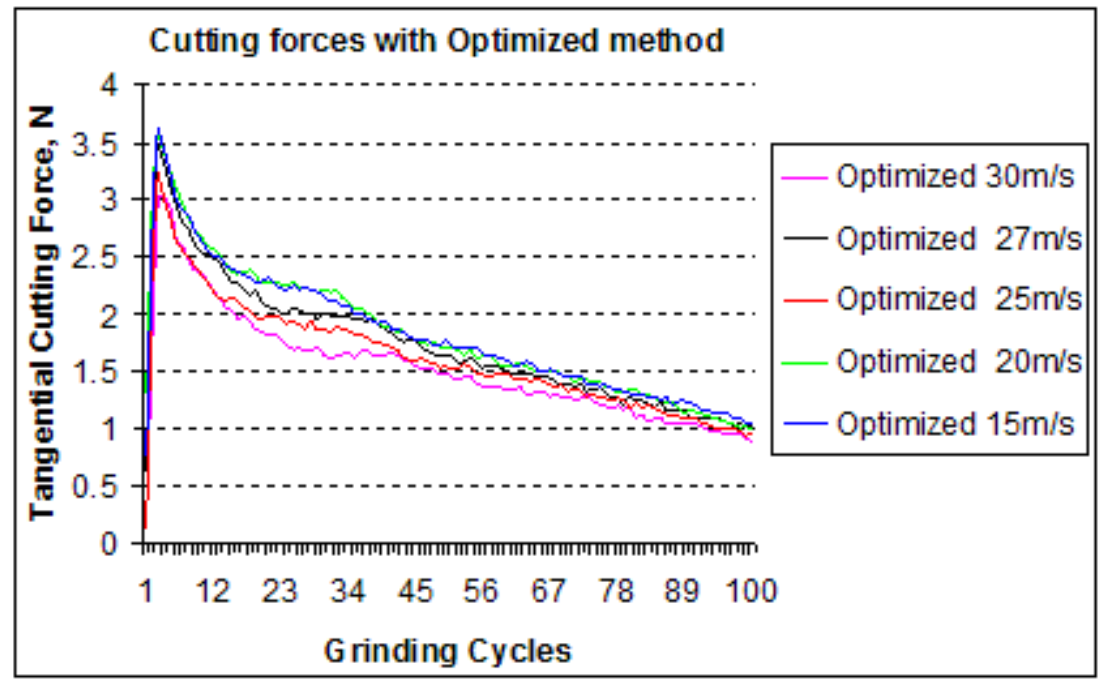

Figure 3: Analysis of the effect of the Optimized cooling on the tangential cutting forces.

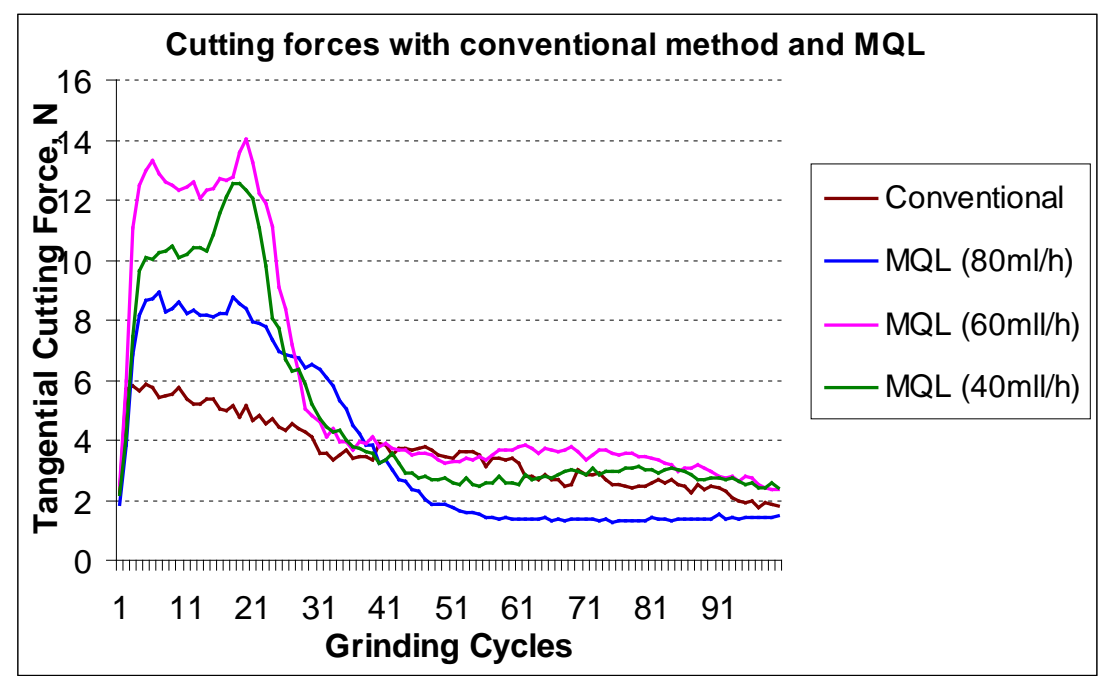

Figure 4: Analysis of the effect of the conventional and MQL cooling on the tangential cutting forces. 
An analysis of Figures 3 and 4 indicate that the cutting forces involved in the MQL processes were much higher than in the conventional and optimized systems.

The optimized system provided very efficient lubrication, reducing the grinding wheel wear and extending its service life. The high velocities involved in the optimized processes favored the fluid jet penetration at the workpiece-wheel interface, reducing the work of friction between the workpiece and the tool.

The conventional system showed an intermediary performance between the optimized and MQL systems in terms of cutting forces. In both the optimized and conventional systems, the apparent loss of sharpness was very subtle in the first 100 machining cycles (close to the 25th cycle in optimized lubrication). This finding indicates that this technique requires fewer wheel dressings, when compared with the MQL method.

With regard to the variation in cutting fluid flow rates of 40,60 and $80 \mathrm{ml} / \mathrm{h}$ for the MQL condition, the cutting force was found to decrease as the fluid flow increased. The condition that presented the best performance compared with conventional lubrication/cooling was the $80 \mathrm{ml} / \mathrm{h}$ flow, which favored lubrication at the wheel-workpiece interface.

The optimized lubrication/cooling tests showed better results than the conventional and MQL methods, and the lowest tangential cutting forces observed with the optimized method were achieved with a cutting fluid flow velocity of $30 \mathrm{~m} / \mathrm{s}$.

The optimized technique presented lower tangential cutting forces than the conventional and MQL systems. However, the cutting force values obtained fell within an acceptable range for grinding processes.

These results are according with Kovacevic and Mohan [4]. They showed that normal and tangential forces can be reduced with an increase in the coolant jet speed.

According to Nguyen et al. [20], due to poor cleaning provided by the MQL method, a large number of pollutants might be either loaded onto the wheel or embedded into the ground material, thus produced higher grinding forces.

\subsection{Acoustic Emission}

Due to the low cost and the size of current sensors for measuring the acoustic emission generated during machining processes, this technique should begin to be employed frequently on an industrial scale. Figures 5 and 6 illustrate the maximum mean acoustic emissions signals of the five repetitions carried out for each of the MQL, OM and CM conditions employed, allowing for their evaluation and comparison.

From a comparison of the machining conditions using the MQL, optimized and conventional lubrication/cooling techniques, it can be seen that the behavior of the conventional was more constant than MQL and that it generated the lowest values of acoustic emission.

The MQL test also showed that after the 20th grinding cycle, the minimum acoustic emissions were close to the blank emission levels. No significant differences were detected in the minimum emissions as a function of the cutting fluid flow applied in each MQL condition.

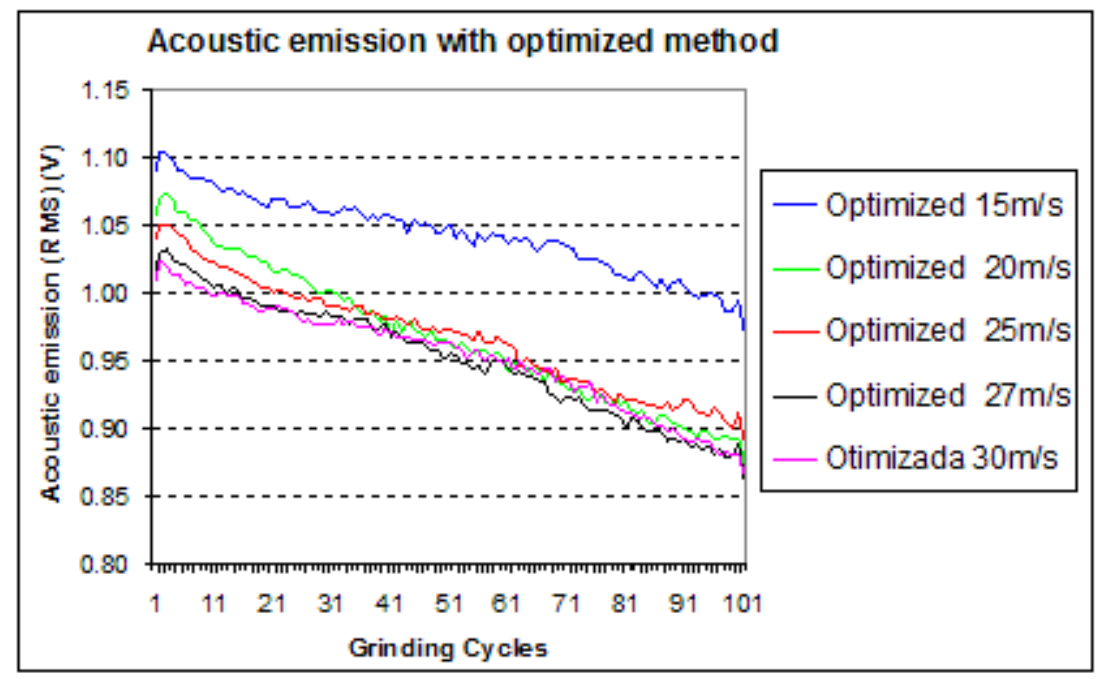

Figure 5: Analysis of the effect of the optimized cooling on the acoustic emission. 


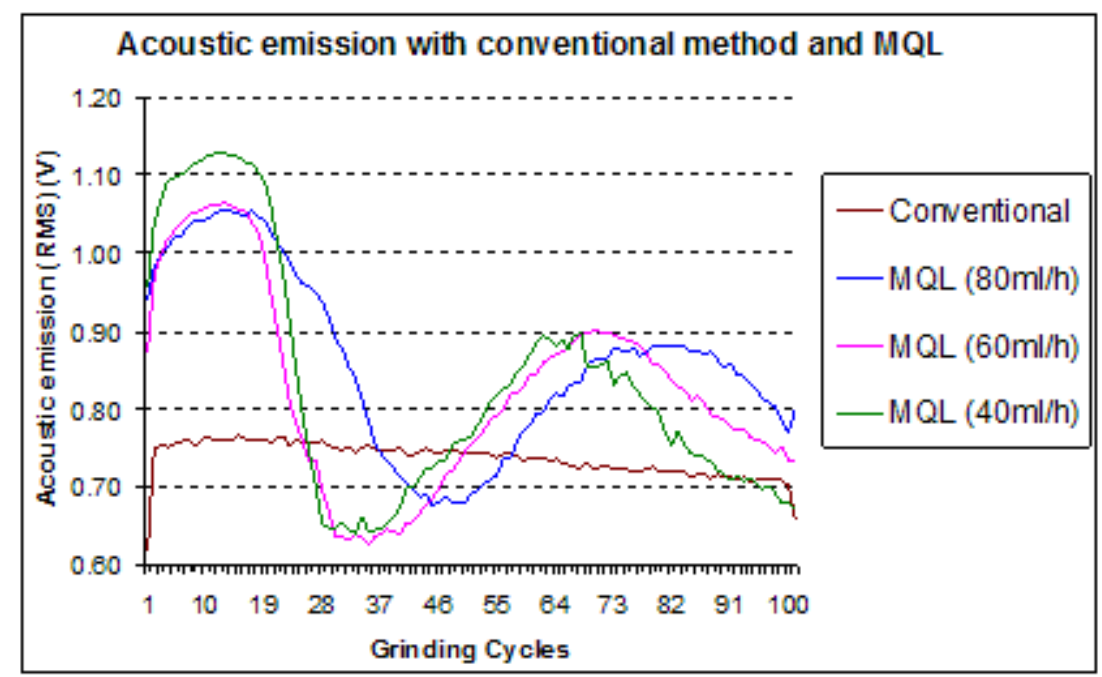

Figure 6: Analysis of the effect of the conventional and MQL cooling on the acoustic emission.

The acoustic emissions in the optimized and conventional methods were more constant and had lower variation, indicating that these forms of lubrication were able to maintain the grinding wheel sharpness throughout the machining cycles.

According to Inasaki [14], there is a relation between grinding specific energy and acoustic emission values, which was confirmed by their tendency to minimize as the cutting fluid flow rates increased.

\subsection{Surface Roughness}

The importance of analyzing this variable lies in the fact that the surface finish strongly affects the fatigue strength of manufactured components subjected to fatigue loads. The surface roughness of a workpiece is directly related to lubrication and depends principally on the size of the abrasive grains in the grind wheel, the dressing conditions, the rate of removal, spark-out time and lubrication/cooling conditions (MALKIN [1]).

Figure 7 shows the mean surface roughnesses of the five repetitions carried out for each of the MQL, OM and CM conditions employed here.

An analysis of the results indicates that the surface roughness values were generally lower in optimized lubrication/cooling, followed by the conventional method and lastly by MQL. The lowest surface roughness values obtained with MQL were obtained using a lubricant flow of $80 \mathrm{ml} / \mathrm{h}$, thus confirming that the larger amount of fluid lead to lower surface roughness values due to the greater lubrication it provided.

The conventional lubrication/cooling method resulted in lower surface roughness values than the MQL technique, but the values obtained with a lubricant flow of $80 \mathrm{ml} / \mathrm{h}$ are lower roughness values than those of the majority of industrial applications.

The best optimized situation (fluid flow velocity of $20 \mathrm{~m} / \mathrm{s}$ ) with respect to the mean surface roughness, Ra, of the workpiece was $71.7 \%$ lower than the best MQL condition $(\mathrm{Q}=80 \mathrm{ml} / \mathrm{h})$ and $47 \%$ lower than the conventional cutting fluid dispensing method.

The lowest values attained with the optimized method were obtained at higher cutting fluid flow rates, thus confirming that a larger quantity of fluid allowed for lower surface roughness values due to the greater lubrication it provided. Higher cutting fluid flow rates allow for more rapid chip removal, contributing to a better finish. The differences in surface roughness between the optimized conditions were minor, but showed a tendency for better quality at higher cutting fluid flow rates.

According to Sinot (2006) [21], the flow rate needs to be high to ensure the efficiency of the grinding process, favoring the cleaning of the grinding wheel.

Morgan et al. (2008) [16] says that a tangentially directed jet can easily disrupt the air barrier if the jet speed equals wheel speed. Webster et al. (1995) [5] showed the need for jet coherency.

The results differ from results obtained by Silva et al (2006) [6]. Silva et al. (2006) [6] showed the effectiveness of the MQL technique in the external cylindrical grinding process by comparing with the 
conventional cooling method. The surface roughness values significantly decreased with the use of MQL method.

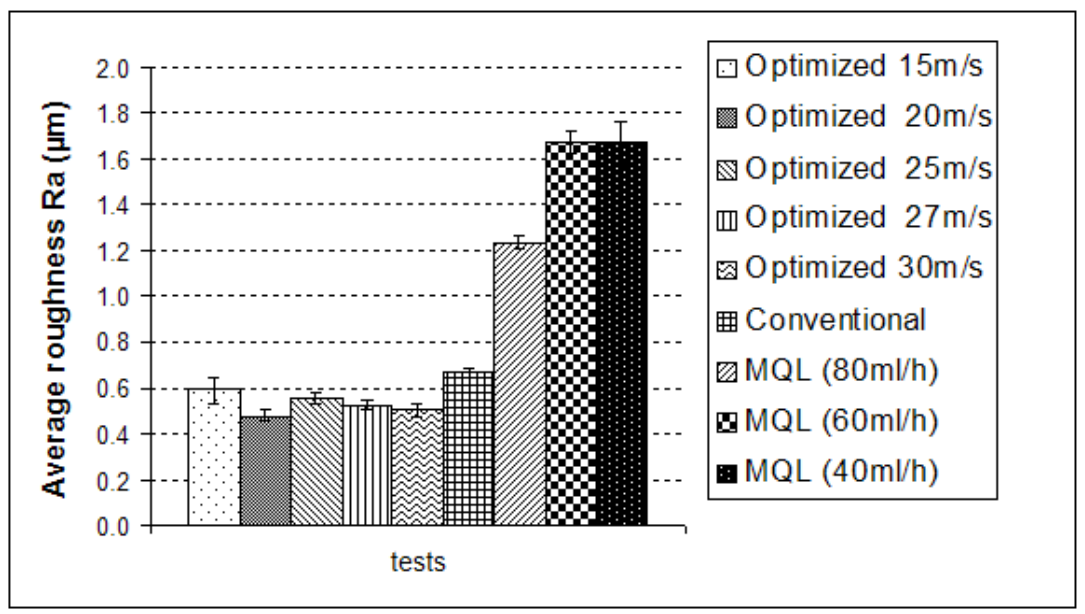

Figure 7: Analysis of the effect of the cutting fluid dispensing methods on surface roughness.

\subsection{Roundness Errors}

Figure 8 depicts the results of roundness errors in the five repetitions carried out for each of the MQL, OM and CM conditions.

An analysis of the roundness results indicates that, in general, the values did not show significant differences in each of the conditions using the optimized technique. Moreover, the optimized technique showed better roundness results than did the conventional and MQL methods.

The amount of cutting fluid in the MQL technique proved of fundamental importance to roundness errors.

The optimized condition with a fluid flow rate of $30 \mathrm{~m} / \mathrm{s}$ presented lower roundness errors than the other conditions and the other lubrication/cooling techniques. The mean roundness error for this condition was $2 \mu \mathrm{m}$, and was $70.5 \%$ lower than the best MQL condition obtained with a flow rate of $80 \mathrm{ml} / \mathrm{h}$. of $60 \mathrm{ml} / \mathrm{h}$.

The highest roundness error was $7.9 \mu \mathrm{m}$, obtained in the MQL condition with a lubricant flow rate

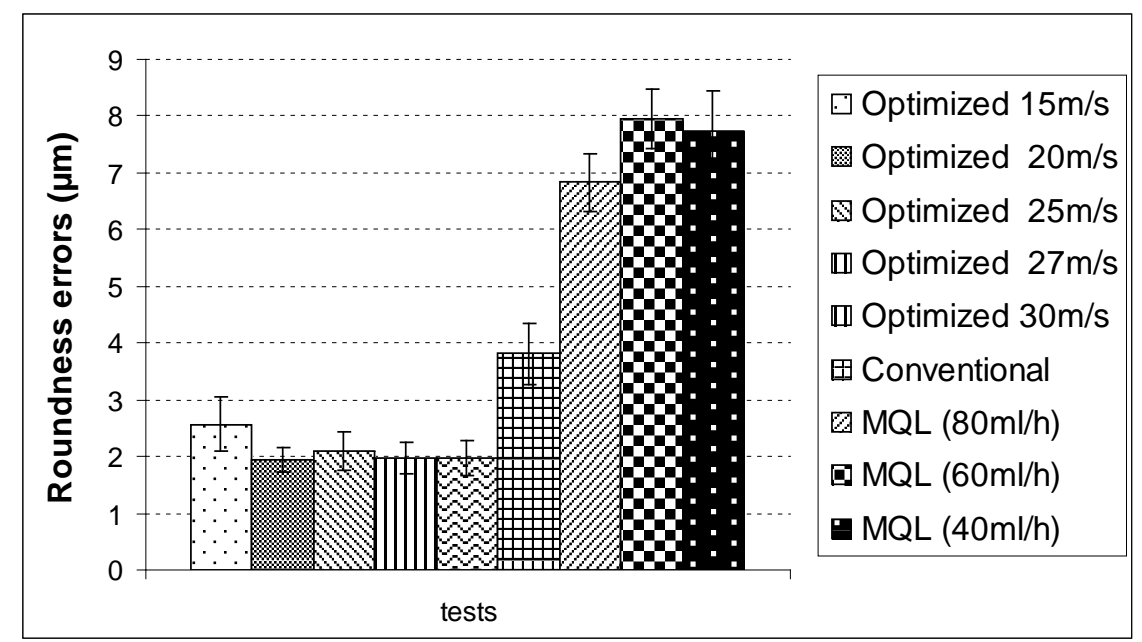

Figure 8: Analysis of the effect of the cutting fluid dispensing methods on roundness errors.

As for the flow rates used in the optimized lubrication/cooling method, a tendency was found for roundness to improve in response to higher cutting fluid flow rates. 
Another relevant factor, according to Kohli et al. (1995) [15], is the fact that the thermal conductivity of CBN grains enables less heat to be directed to the workpiece, thus facilitating its dimensional control and ensuring the surface integrity of the machined component.

\subsection{Microhardness}

Figure 9 illustrates the mean Vickers microhardness results obtained for each of the MQL, OM and CM conditions. This figure also shows the mean Vickers microhardness obtained in the burn test of a turned workpiece.

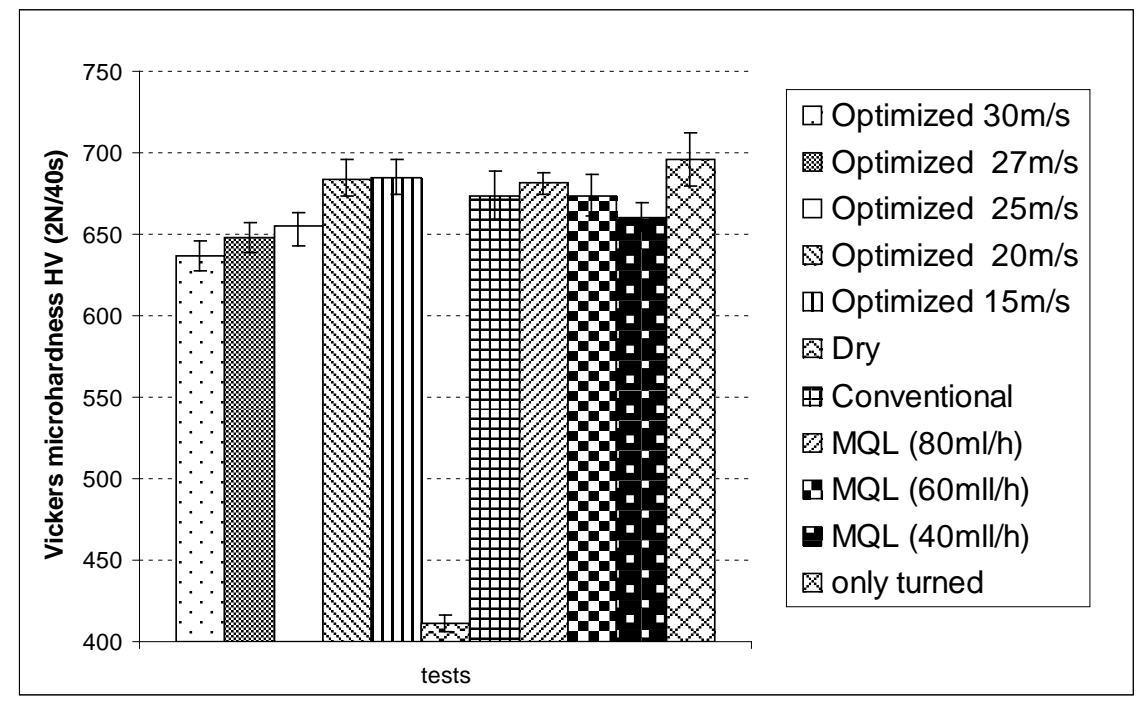

Figure 9: Mean Vickers microhardness values attained with the MQL, OM and CM techniques; burn test on turned workpiece.

The highest mean variation in hardness in relation to the original (turned) workpiece was found in the MQL condition with a fluid flow rate of $40 \mathrm{~m} / \mathrm{s}$, which presented $5.1 \%$ lower hardness, on average, than the turned workpiece. This was the worst (lowest hardness) condition with respect to the Vickers microhardness output variable for the MQL condition. The best MQL condition was attained with the flow rate of $80 \mathrm{ml} / \mathrm{h}$, which presented a $2.15 \%$ lower hardness than the turned workpiece.

The analysis of the microhardnesses obtained with the MQL, CM and OM techniques led to the conclusion that, regardless of the efficiency of the lubrication/cooling method employed, there is a slight loss of surface hardness. It was also concluded that the highest cutting fluid flow rate $(80 \mathrm{ml} / \mathrm{h})$ in the MQL technique leads to lower loss of hardness. However, generally speaking, none of the techniques proved more efficient than the others, in general terms.

The Vickers microhardness for the best optimized condition was practically the same as that attained with the best MQL condition, with a difference of less than $1 \%$.

Similar results were observed by Nguyen et al. (2003) [20]. The result showed that the hardness of the component ground with MQL method was more or less the same as that ground with conventional method. It suggests that the improvement of lubrication by a small amount of vegetable oil in the air stream could significantly

\subsection{Residual Stresses}

Figure 10 depicts the results of mean residual stress for the MQL, OM and CM conditions used here. The value of the mean residual stress for the burn test on the turned workpiece is also shown.

Figure 10 indicates that the stresses were compressive. This was first reported by Brinksmeier et al. (1982) [13], using CBN grinding wheels. The higher thermal conductivity of CBN allows for smaller portion of the heat to enter the workpiece, thus reducing the thermal effects. 


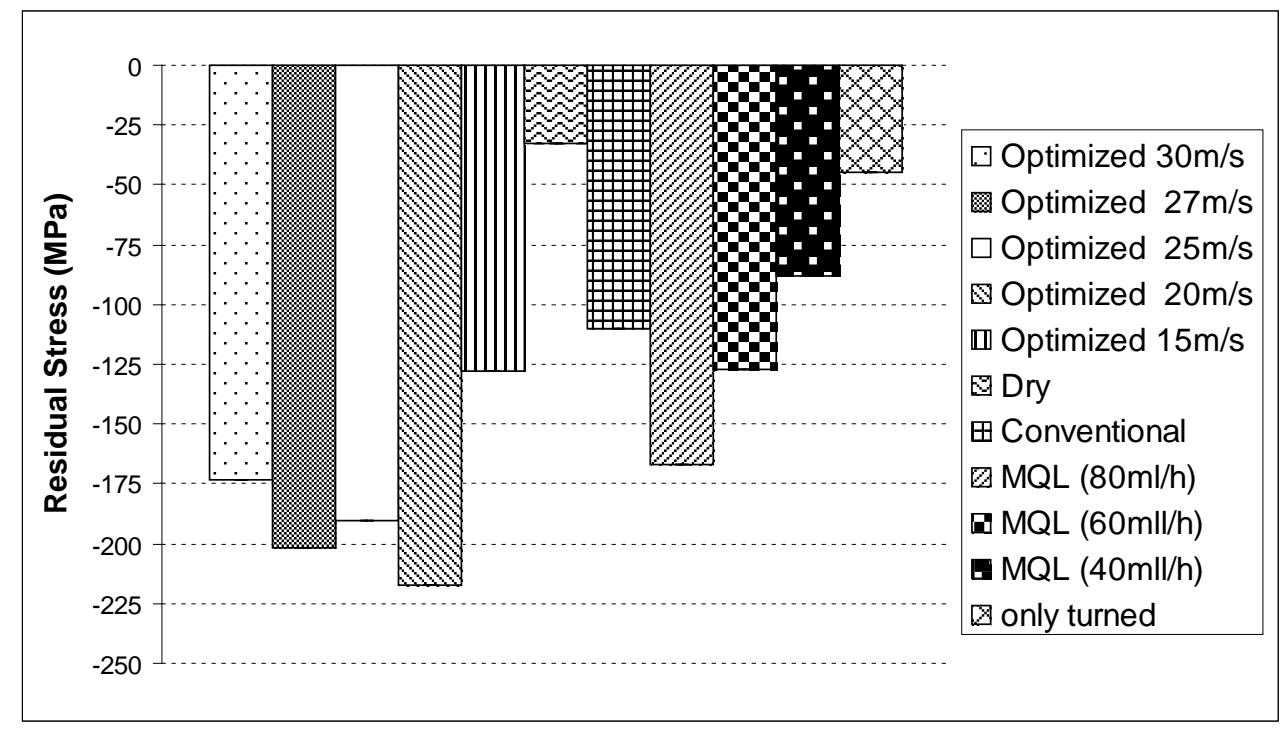

Figure 10: Analysis of the effect of the cutting fluid dispensing methods on residual stress.

\subsection{Microstructural Analysis}

The surface integrity of a workpiece is an extremely important factor, and damage of the surface of a material may affect it significantly, causing degradation of the properties of wear and corrosion resistance, crack nucleation and propagation, and acceleration of the components fatigue process. The surface integrity of the workpiece is affected mainly by the temperature generated by the grinding process, which may lead to its thermal damage.

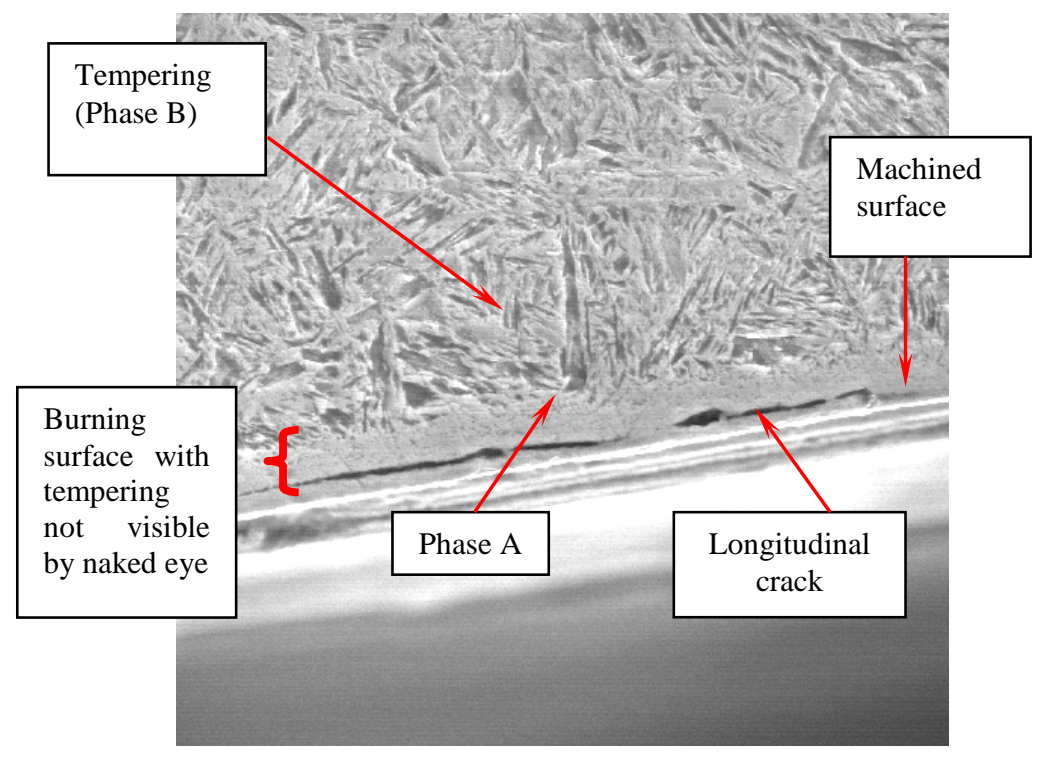

Figure 11: Micrograph of a test specimen subjected to MQL with cutting fluid flow of 40ml/h (2000 X magnification).

The conventional method lubricated and cooled the workpiece efficiently, without allowing it to sustain damage. The same holds true to optimized lubrication/cooling. In addition, the contact time of the abrasive grains and the cooling time are very short, thus not leading to significant differences at the subsurface. 
The MQL conditions of $80 \mathrm{ml} / \mathrm{h}$ and $60 \mathrm{ml} / \mathrm{h}$ did not lead to substantial subsurface alterations of the microstructure when using the MQL technique.

The microstructure depicted in Figure 11 corresponds to the MQL condition of $40 \mathrm{ml} / \mathrm{h}$. In this condition it was possible to detect significant subsurface changes in the microstructure, such as cracks and surface burn.

Nguyen et al. (2003) [20] suggests that the improvement of lubrication by a small amount of oil in the air flow could significantly reduce the thermal impact on the workpiece. This was observed for MQL method with a flow rate of 60 and $80 \mathrm{ml} / \mathrm{h}$.

An analysis of the microstructure indicated that the various conditions tested in this study using the optimized and conventional lubrication/cooling techniques showed satisfactory results. In other words, no significant microstructural changes or surface damage of the workpiece were found after grinding, thus improving the component properties of corrosion resistance and abrasive strength and enhancing its fatigue strength. The only exception was the situation in which a cutting fluid flow rate of $40 \mathrm{ml} / \mathrm{h}$ was used with the MQL technique, which showed the presence of cracking and surface hardening, albeit without visually detectable burn.

\section{CONCLUSIONS}

From the results of tangential cutting forces and acoustic emission, it was concluded that the use of the MQL system with a compressed air outlet velocity of $30 \mathrm{~m} / \mathrm{s}$, CBN grinding wheel and a cutting velocity of $30 \mathrm{~m} / \mathrm{s}$, should be used for a maximum equivalent cutting depth (heq) of approximately $0.060 \mu \mathrm{m}$. Because the equivalent cutting depth depends on the diameter of the workpiece, the plunge velocity and the cutting velocity, these parameters should be suitably adjusted to enable the grinding wheel to cut (lowest removal per abrasive grain) and the MQL system to remove the chips from the wheel pores.

The optimized technique was found to be essential to produce more precise workpieces than those produced with the other two techniques, and therefore offers an option to obtain higher quality components without changing grinding wheels, cutting fluid, and dressing and cutting conditions.

Higher flow volumes and cutting fluid application velocities lead to better results for the machined material, producing lower roughnesses and smaller roundness errors.

This study indicated that it is possible to use CBN grinding wheels with smaller quantities of abrasive grains associated to more efficient forms of applying cutting fluids, without impairing the properties of the machined components, contributing to reduce the costs of the grinding process.

Cutting fluids that are less harmful to the environment and to human health, such as the ones used in this research, proved feasible for use in grinding processes, without impairing the quality of the workpieces, thus contributing to reduce impacts on health and nature.

With regard to the surface integrity of workpieces, the SEM images and microhardness values revealed that the properties of the material did not change in any of the optimized and conventional conditions due to the lubricating efficiency of these methods.

In the case of the MQL technique, the fluid flow rates of $80 \mathrm{ml} / \mathrm{h}$ and $60 \mathrm{ml} / \mathrm{h}$ did not produce any detectable thermal effects. However, the MQL condition with a flow rate of $40 \mathrm{ml} / \mathrm{h}$ led to appearance of cracking and surface hardening due mainly to the smaller amount of lubricant delivered, causing greater heat generation due to the friction between grain and workpiece. But the results of roundness errors with MQL were poor. The surface roughness results indicate that the MQL method cannot replace other methods.

All the variables analyzed here were significantly reduced with the application of the optimized technique due to the good lubrication and cooling provided, and due to the efficiency of the innovative nozzle model employed.

The conditions of cutting fluid and compressed air flow rates used with the MQL technique did not cause misting, giving the operator a good view of the grinding process and favoring environmentally correct machining.

Although a hard open-structured CBN grinding wheel with a low concentration of CBN grains (15\% in volume) and fine grain size (100 to 200 mesh) was used, the results of the MQL technique were satisfactory, since they fell within acceptable limits for grinding.

It was found that a cutting jet velocity close to the cutting velocity led to the best results, since in this condition breaks the aerodynamic barrier around the grinding wheel, favoring the entrance of fluid and providing more efficient chip removal, thus reducing its effects on the workpiece. Nevertheless, there is still need for more in-depth studies at higher jet velocities in relation to the cutting velocity. 


\section{ACKNOWLEDGEMENTS}

The authors are indebted to FAPESP - State of São Paulo Research Foundation (Brazil) for its financial support of this research.

\section{REFERENCES}

[1] MALKIN, S., "Grinding mechanisms e grinding temperatures and thermal damage”, In: MALKIN, S. "Grinding Technology: theory and applications of machining with abrasives", 1.ed. Chichester, Ellis Horwood Limited, Cap. 5 e 6, pp. 108 a 171, 1989.

[2] GUO, C., "Energy partition and cooling during grinding”, In: 3rd International Machining \& Griding Conference, SME, Cincinnati, Ohio, USA, pp. 1-12, Oct. 4-7, 1999.

[3] WEBSTER, J. A., "Optimizing coolant application systems for high productivity grinding", Abrasives Magazine, pp. 34-41, Oct.-Nov., 1999.

[4] KOVACEVIC, R. MOHAN, R., "Effect of high speed grinding fluid of surface grinding performance", In: SME Technical Paper of the First International Machining and Grinding Conference, Society of Manufacturing Engineers, pp. 919-931, 1995.

[5] WEBSTER, J.A., CUI, C. MINDEK Jr., R.B., “Grinding fluid application system design”, In: Annals of the CIRP, v. 44, pp. 333-338, 1995.

[6] SILVA, L.R., BIANCHI, E.C., FUSSE, R.Y., et al., "Analysis of surface integrity for minimum quantity lubricant - MQL in grinding”, International Journal of Machine Tools and Manufacture, v. 47, pp. 412-418, 2006.

[7] CATAI, R.E., SILVA, L.R. , BIANCHI, E.C., et al., "Performance of aerodynamic baffles in cylindrical grinding analyzed on the basis of air layer pressure and speed", Journal of Brazilian Society of Mechanic Science \& Engineering, v. 30, n. 1, pp. 47-50, Jan. - March 2008.

[8] WEBSTER, J., "Selection of coolant type and application technique in grinding”, Supergrind, pp. 205218, 1995.

[9] HAFENBRAEDL, D. MALKIN, S., "Environmentally-conscious minimum quantity lubrification (MQL) for internal cylindrical grinding", NANRI Society of Manufacturing Engineers, v. 28, pp. 149-154, 2001.

[10] UPADHYAYA, R.P. MALKIN, S., "Thermal aspects of grinding with electroplated CBN wheels," ASME Journal of Manufacturing Science Engineering, v. 126, pp. 107-114, 2004.

[11] ITOIGAWA, F., CHILDS, T.H.C., NAKAMURA, T., et al., "Effects and mechanisms in minimal quantity lubrication machining of an aluminum alloy", Wear, v. 260, n. 3, pp. 339-344, 2006.

[12] EBBRELL, S., WOOLLEY, N.H., TRIDIMAS, Y.D., et al., "The effects of cutting fluid application methods on the grinding process", International Journal of Machine Tools \& Manufacture, v. 40, pp. 209-223, 2000.

[13] BRINKSMEIER, E., CAMMETT J.T., KÖNIG, W., et al., "Residual stresses - measurement and causes in machining processes”, In: Annals of the CIRP, v. 31, pp. 491-510, 1982.

[14] INASAKI, I., "Monitoring and optimization of internal grinding process", In: Annals of the CIRP, v. 40, pp. 359-362, 1991.

[15] KOHLI, S.P., GUO, C. and MALKIN, S., "Energy Partition for Grinding with Aluminum Oxide and CBN Abrasive Wheels”, ASME Journal of Engineering for industry, v. 117, pp. 160-168, 1995.

[16] MORGAN, M.N., JACKSON, A.R., WU, H., et al., "Optimisation of Fluid Application in Grinding”, In: Annals of the CIRP, v. 57, pp. 363-366, 2008. 
ALVES, M.-C.; BIANCHI, E.-C.; AGUIAR, P.R.; CANARIM, R.-C.; Revista Matéria, v. 16, n. 3, pp. 754 - 766, 2011.

[17] FAGOR AUTOMATION DO BRASIL, http://www.fagorautomation.com.br, acessado em junho de 2011.

[18] SHELL DO BRASIL, http://www.shell.com/home/content/br, acessado em junho de 2011.

[19] ITW CHEMICAL PRODUCTS LTDA., http://www.itwchem.com.br, acessado em junho de 2011.

[20] NGUYEN, T., ZHANG L.C., "An assessment of the applicability of cold air and oil mist in surface grinding”, Journal of Materials Processing Technology, v. 140, n. 1-3, pp. 224-230, 2003.

[21] SINOT, O., CHEVRIER, P., PADILLA, P., "Concrete International, "Experimental simulation of the efficiency of high speed grinding wheel cleaning", International Journal of Machine Tools and Manufacture, v. 46, pp.170-175, 2006. 